\title{
Lithic Technological Variability of the Middle Pleistocene in the Eastern Nihewan Basin, Northern China
}

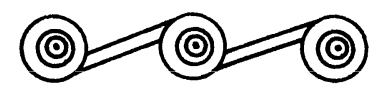

CHEN SHEN AND WEI QI

Until ReCently, StUdies of Paleolithic TeChNology in China have been limited to generalizations about the nature of lithic industries in comparison to European or other Old World localities. From the "chopper-chopping tool tradition" (Movius 1944, 1948, 1969) to the "simple core-flake technology" (Schick 1994, 1998; Schick and Dong 1993), these broad characterizations emphasize the non-Acheulean features of the Early to Middle Pleistocene lithic industries in East Asia. This emphasis on technological differences between the East and the West has hampered the study of lithic technological variability from a regional perspective, even though it may reflect early hominid adaptations unique to East Asia.

Based on accumulated data in the last two decades, Chinese researchers have recognized two major lithic industries: the pebble/core tool industry in the central-south and the southeast, and the flake tool industry in the north as well as the southwest ( $\mathrm{Lu}$ 1999; Olsen and Miller-Antonio 1992; Wang 1997, 2001; Zhang 1999). The two industries, each represented by their unique use of raw materials, core reduction modes, and tool utilization, persisted over the entire Pleistocene with slight changes in spatial distribution (Wang 1997). These technological differences within mainland China have been attributed to regional adaptations to paleoenvironments. Thus analyses of lithic artifacts from Lower Paleolithic sites have been given some attention in a number of recent studies, furnishing technological and statistical data for regional comparison (Chen et al. 1999, 2002; Gao 2000a, b, 2001; Hou 1992, 2000; Huang et al. 1997; Keates 2000; Leng 2001; Shen and Chen 2000, 2001, 2003). These studies have enabled us to characterize the complexity of lithic technological variability of the Lower Paleolithic in China. In this paper, we will concentrate on two lithic assemblages from Middle Pleistocene sites in the eastern Nihewan Basin: Cenjiawan and Maliang. The study of the Cenjiawan lithic assemblage has been published else-

Chen Shen is with the Department of World Cultures of the Royal Ontario Museum in Toronto, Canada. Wei Qi is with the Institute of Vertebrate Paleontology and Paleoanthropology in Beijing, China. 


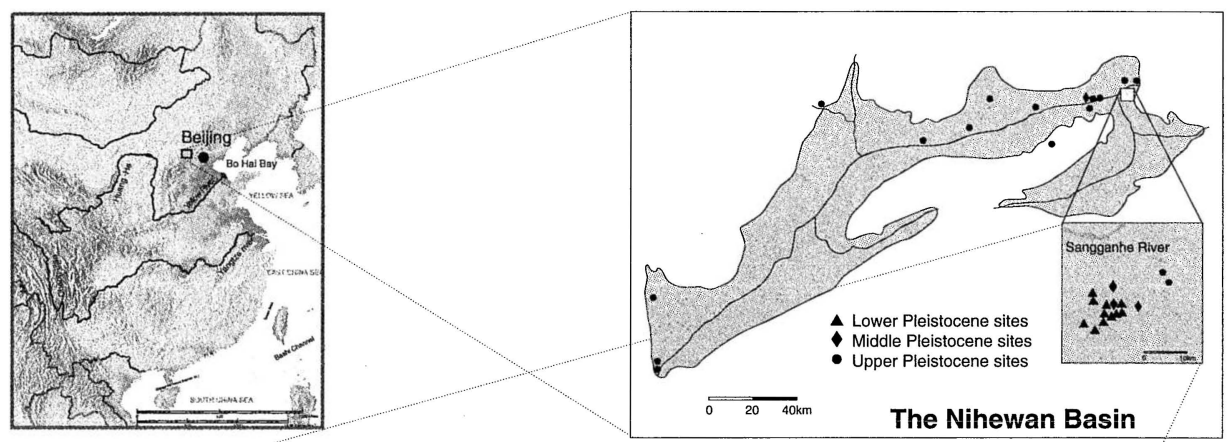

China
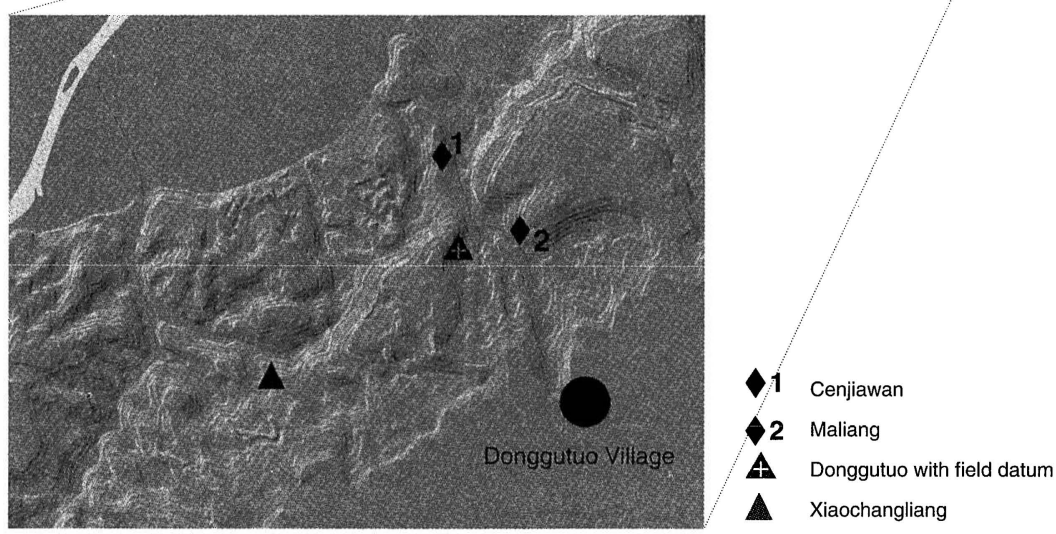

The Study Region

Fig. 1. Maps showing the location of sites in the study.

where (Xie and Chen 1990; Xie and Li 1995; Xie et al. 1994). However, the report is in Chinese and inaccessible to most Western readers. Therefore, we will first give a summary of the Cenjiawan materials, following a brief introduction of the study region. The results of the technological and functional analyses of lithic artifacts from the Maliang site are presented. Technological variability of the Lower Paleolithic will be discussed at the end of the paper with comparative data drawn from other Paleolithic sites in northern China.

\section{THE NIHEWAN BASIN}

The Nihewan Basin is located in northwestern Hebei Province, approximately $150 \mathrm{~km}$ west of Beijing (Fig. 1). Geological investigations suggest that the Nihewan Basin, at an altitude of $800-1000 \mathrm{~m}$ above sea level, was formed from hundreds of meters of fluvial lacustrine sediments accumulated over millions of years. This archaic lake dried up about 25,000 years ago (Wei 1997; Xia 1992). Ancient lake shorelines were identified suggesting three major and seven smaller cycles of expansion and reduction of the lake level (Wei 1991, 1997; Xia 1992). Thus most, if not all, of the Early and Middle Pleistocene sites were lake-side occupations. The discovery of Pliocene-Pleistocene mammal fossils in the early 1920s (Barbour 1924; Barbour et al. 1927) established the potential of this area as a possible early hominid locality. Since the 1960s, over 40 archaeological sites or 
localities have been identified from the Basin (Wei 1997). Lower and Middle Pleistocene sites are concentrated in the eastern end of the Basin, while upper Pleistocene sites are spread widely across the Basin (Fig. 1).

Based on the geological formation and biostratigraphic evidence, Wei (1991, 1997) established a chronological framework of the archaeological sites in the $\mathrm{Ba}-$ sin (also see Pope and Keates 1994; Schick et al. 1991). Paleomagnetic dating has been the only suitable dating method able to verify age limits of these sites in corresponding sedimentary layers. The earliest site dates to over one million years ago. Within Nihewan lithostratigraphy, a layer of thick brown sand (or TBS) is recognized as a reference sediment linking deposits among archaeological sites in areas of active faulting. The Cenjiawan site is located about one meter below the TBS layer and dates to approximately 900-970 kya BP (Wei 1991, 1997; Xie and Li 1993), while the Maliang site is above the TBS and has an estimated age of no older than 730 kya BP (Wei 1991, 1997).

Since the late 1980s, archaeological investigations in the Nihewan Basin have been undertaken by a number of joint international teams. These collaborations have brought new field methods and analytic techniques unprecedented to the study of the Nihewan archaeological materials. Although the two sites being studied here were excavated prior to these collaborations, the lithic artifacts were re-examined as part of these collaborative efforts.

\section{THE CENJIAWAN SITE}

The Cenjiawan site, first identified in 1984, is situated on a hillside, about $837 \mathrm{~m}$ from the Donggutuo field datum $\left(40^{\circ} 13^{\prime} 22.5^{\prime \prime} \mathrm{N}-114^{\circ} 40^{\prime} 16.5^{\prime \prime} \mathrm{E}\right)$ with a bearing of $8^{\circ} \mathrm{SW}$, at an elevation of $869.60 \mathrm{~m}$ above sea level (Fig. 1). Archaeologists from the Hebei Provincial Institute of Archaeology and Cultural Relics undertook a small-scale excavation at Chenjiawan in 1986, yielding 897 lithic artifacts (Xie and Chen 1990). Faunal remains were collected, but no counts were reported (Xie and Chen 1990). Schick et al. (1991) mentioned that there were faunal remains numbering about 100 . The excavators recognized that the artifacts were found in clusters at the site, suggesting this may be indicative of activity areas. Unfortunately, precise provenances of the artifacts (3D coordinates) were not available from this field season.

The second fieldwork season took place in 1992 when the excavation was better controlled and artifacts were piece-plotted (Xie and Li 1993). The excavation trench, about $10 \mathrm{~m} \mathrm{~N}-\mathrm{S}$ by $2 \mathrm{~m} \mathrm{E-W}$, was laid out at the west end of the previous excavated area. The second field season yielded a total of 486 lithic artifacts and 206 bone fragments. In addition, lithic debris and bone fragments were discovered through dry screening. The faunal remains consisted of mainly fragments of elephants and Proboscidipparion-Equus. Ninety percent of the recovered bones were heavily eroded and weathered (Xie and Li 1993:231). Most of the artifacts were recovered from four one-by-one-meter squares $(N, O, P, Q)$, forming a small concentration of artifacts within the entire $20 \mathrm{~m}^{2}$ excavation area.

\section{The Lithic Assemblage}

A combined total of 1383 lithic artifacts were recovered from two field seasons. Table 1 shows the classification of lithic artifacts according to the two original 
Table i. Lithic Assemblage of Cenjiawan

\begin{tabular}{|c|c|c|c|c|c|c|}
\hline \multirow[b]{2}{*}{ CLASS } & \multicolumn{2}{|c|}{ I986 EXCAVATION } & \multicolumn{2}{|c|}{ I992 EXCAVATION } & \multicolumn{2}{|c|}{ COMBINED } \\
\hline & $\mathrm{N}$ & $\%$ & $\mathrm{~N}$ & $\%$ & $\mathrm{~N}$ & $\%$ \\
\hline Cores & 23 & 2.6 & 13 & 2.7 & 36 & 2.6 \\
\hline Formed Types & 26 & 2.9 & 7 & 1.4 & 33 & 2.4 \\
\hline side-scrapers & \multicolumn{2}{|c|}{25} & \multicolumn{2}{|c|}{4} & \multicolumn{2}{|c|}{29} \\
\hline end-scrapers & \multirow{2}{*}{\multicolumn{2}{|c|}{$\begin{array}{l}1 \\
0\end{array}$}} & \multicolumn{2}{|c|}{1} & \multicolumn{2}{|c|}{2} \\
\hline notches & & & \multicolumn{2}{|c|}{2} & \multicolumn{2}{|c|}{2} \\
\hline Debitage & 848 & 94.5 & 283 & 58.2 & 1131 & 81.8 \\
\hline complete flakes & \multirow{2}{*}{\multicolumn{2}{|c|}{$\begin{array}{r}97 \\
751\end{array}$}} & & & & \\
\hline flake fragments & & & \multicolumn{2}{|c|}{202} & \multicolumn{2}{|c|}{953} \\
\hline Debris (chucks) & & & 183 & 37.7 & 183 & 13.2 \\
\hline Total & 897 & 100.0 & 486 & 100.0 & 1383 & 100.0 \\
\hline
\end{tabular}

reports (Xie and Chen 1990; Xie and Li 1993). In our study, the four main classes of artifacts include cores, formed types, debitage, and debris. The formed types are those with intentional modifications made by employing either surface or edge retouch so as to form certain shapes that traditional lithic typologists would categorize as tools, such as scrapers, burins, choppers, etc. Debitage includes flakes that were likely removed with the intention of producing tool blanks, or at least they were flakes with potential to be used directly (or unmodified) as tools. This property of debitage flakes being used as tools is also the reason we renamed the traditional category "tool" for shaped objects to "formed types." In contrast, debris consists of unexpected waste products of core reduction. They are small chips and angular chunks formed as blow-off by-products of the flint knapping process. Debris has no potential to be modified and used as tools whatsoever, but its presence in archaeological sites is numerous and the spatial distribution is a good indication of manufacturing activities on site.

Clearly, in the first season, the excavators did not give much attention to debris, as only large complete flakes along with cores and formed types were recorded. Even in the second field season when dry-screening was applied, according to the reports, the excavators classified only cores, tools, complete flakes, flake fragments, and chunks. Therefore, if the site indeed represented a manufacturing area as indicated by the data below, then artifacts in the debris class should be more numerous than is noted here.

According to the reports, 36 cores consist of 25 single-platform cores and 11 with double platforms. Among these, four cores are bipolar. The range of core size is about $17-114 \mathrm{~mm}$ in length, $19-113 \mathrm{~mm}$ in width, and $8-37 \mathrm{~mm}$ in thickness, but most of the cores are small. Core platforms show no intentional preparation. From 23 pieces recovered from the 1985 field season, 11 cores retain some portions of the original surface that may indicate employment of rather small raw materials. Within double-platform cores, the $90^{\circ}$ platform cores $(\mathrm{N}=8)$ outnumber the opposite platform cores $(\mathrm{N}=3)$.

The 33 tools identified in original reports are predominated by side-scrapers; others are end-scrapers and notches (Fig. 2). The retouch method was mostly unifacial on the dorsal surface, evident on 28 pieces. All the tools recovered from 


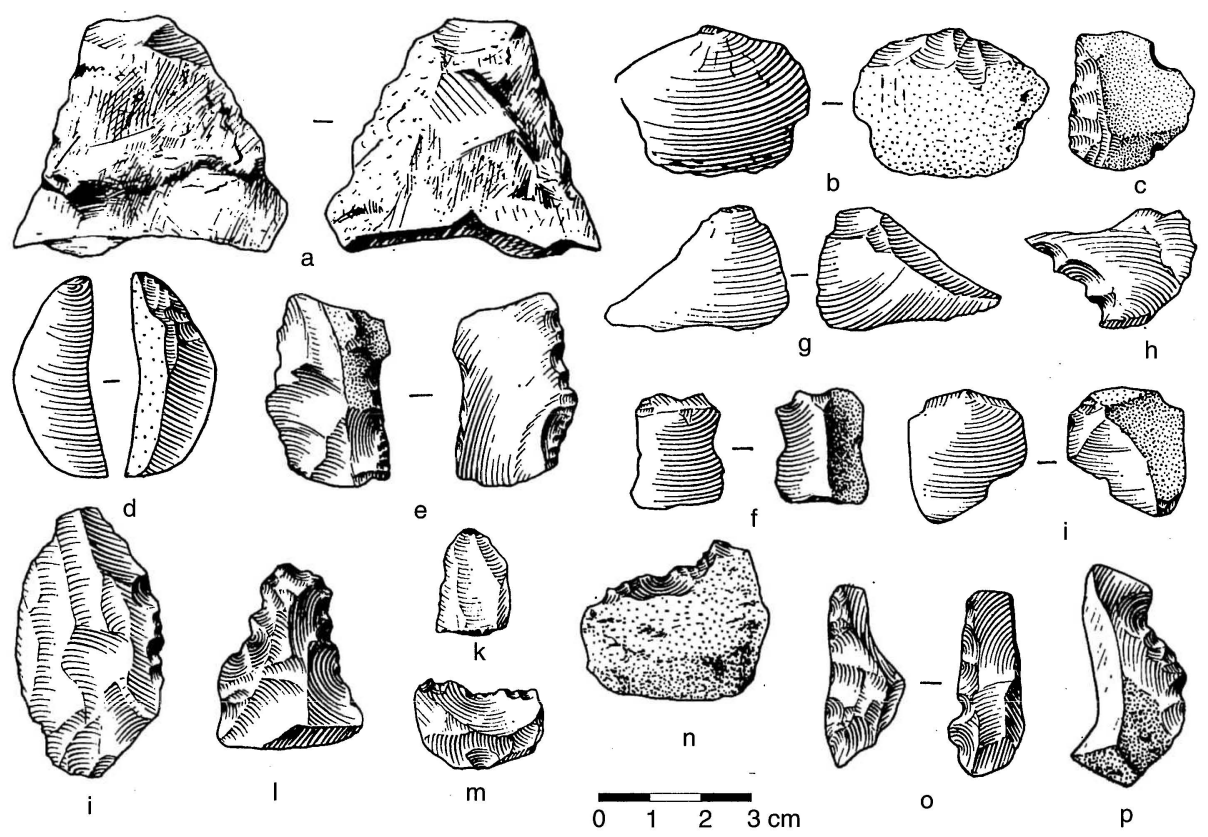

Fig. 2. Lithic artifacts from the Cenjiawan site (after Xie and Chen 1990). Side-scrapers: c, e, h, l, m; notch: p; flake: a, b, f, g, i.

the 1992 field season $(\mathrm{N}=7)$ were found in the artifact concentration area (see above).

One hundred and seventy-eight complete flakes were identified, ranging in size from $11-70 \mathrm{~mm}$ in length and $8-58 \mathrm{~mm}$ in width. The majority of flakes are short and broad (Fig. 2). The excavators suggested that flakes were predominantly produced by hard-hammer percussion and only two pieces were classified as bipolar flakes. Flakes with clear bulb scars account for 52.2 percent of the entire complete flakes, while the rest of the flakes have either no bulb scars or ambiguous bulbs. Ninety-nine pieces display whole or partial cortex on dorsal surface, accounting for 55.6 percent.

Most of the lithic artifacts fall into the category of flake fragment and chunks. The excavators observed macrowear on the edge of some of these flake fragments and chunks, suggesting that these pieces must have been used or had the potential to be selected for tool blanks (Xie and Li 1993). A number of flake fragments and chunks were later refit to flakes, tools, and cores.

\section{Refitting Analysis}

Lithic refitting analysis has been a useful approach to reconstruct methods of core reduction as well as providing information on spatial distribution of activities at a site. Refitting lithic artifacts recovered from Cenjiawan was the first case study of this kind in Chinese lithic analysis. Kathy Schick and Nicholas Toth of Indiana University first introduced the method to their Chinese collaborators in Hebei. The joint team examined the lithic assemblage recovered from the Cenjiawan 
1986 excavation. Out of 897 chipped stone artifacts examined, 131 pieces could be refit, generating the refitting rate of 14.6 percent (Xie et al. 1994). Encouraged with this result, Chinese archaeologists continued this effort after they carried out the second season of excavation in 1992 with careful records of artifact provenience. The result was similar to the previous one: 46 out of 486 lithic artifacts could be refit, yielding a 9.5 percent refitting rate (Xie and $\mathrm{Li} 1995$ ). They believed that an examination of the artifacts from both field seasons would further increase the refitting rate.

All lithic materials were first sorted into clusters on the basis of similarities in raw material variation, color, fracture nature, texture, inclusion, and cortex characteristics. The raw materials of the Cenjiawan lithics are primarily cherts of many varieties derived from volcanic breccias. A total of 25 clusters (two field seasons combined) were recognized; the number of lithic artifacts in each cluster ranges from 1 to 97 , containing combinations of cores, flakes, formed types tools, and fragments. The refitting study yielded 49 refitting sets from the 1986 assemblage and 20 refitting sets from the 1992 assemblage. The number of pieces to have been refit into one single set range from 1 to 10 , although most refitting sets consisted of two pieces each.

One of the best examples of refitting (refitting set \#1-1986) is a reconstructed core consisting of seven complete flakes and two flake fragments (Fig. 3a). All flakes are noncortical on the dorsal surface. The core, about 62 by 40 by $20 \mathrm{~mm}$ in size, retains four platforms, one of which was formed after the removal of the refit flake \#1. The negative flake scars on the core show multidirectional patterns along all edges and surfaces of the core, a characteristic of amorphous cores. The flake removal sequences are reconstructed as follows. After detachment of the flakes prior to the removal of flake \#1, the toolmaker turned over the core to the opposite side and rotated it $90^{\circ}$ to remove flake \#1. Then the knapper turned the core back to the previous surface and rotated it again $90^{\circ}$ back and detached five flakes-\#2, \#3, \#4, \#5-6 (one flake consisted of two fragments), and \#7. It is worth noting that the first two flakes (\#2 and \#3) were removed from an old platform while the latter three were struck off the core from a platform created after the removal of flake \#1. Lastly, the toolmaker turned the core again to the opposite surface and removed flakes \#8 and \#9 before the core was discarded. The core reduction producing the last eight flakes proceeded through at least three rounds of turnover and rotations, and the removal of the flakes involved four platforms. A similar process of core reduction was also reconstructed from the refitting set \#4-1986.

Refitting set \#3 of the 1992 assemblage consists of one core (\#4), one complete flake (\#3), and two fragments (\#1-2) that constitute a single flake (Fig. 3b). The small core has two platforms, a small one (A) and a larger one (B). The small platform $A$, where an elongated and narrow flake was removed, was created after a flake removal from a previous platform (D) at a $90^{\circ}$ angle. Similarly the platform B, opposite to platform A, was also created after a flake was removed from a platform (C). Whether or not this pattern of continuous rotation reduction is indicative of core platform preparation is still not clear. However, from this demonstration, the reduction of this reconstructed core involved $90^{\circ}$ core rotations and at least six flakes were sequentially removed from four platforms of the core.

Set \#1 of the 1992 assemblage is a simple refitting of two flakes (Fig. 3c). 


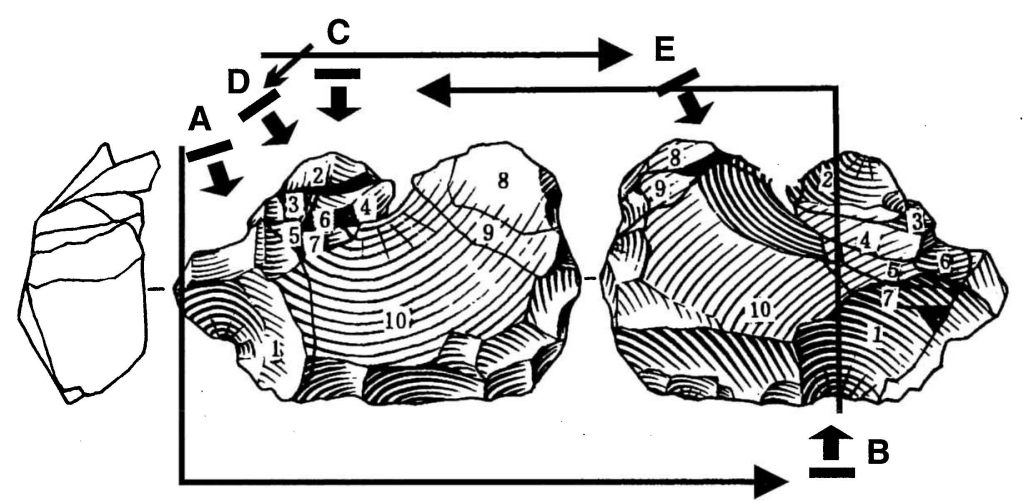

a. Refitting-set \#1-1986
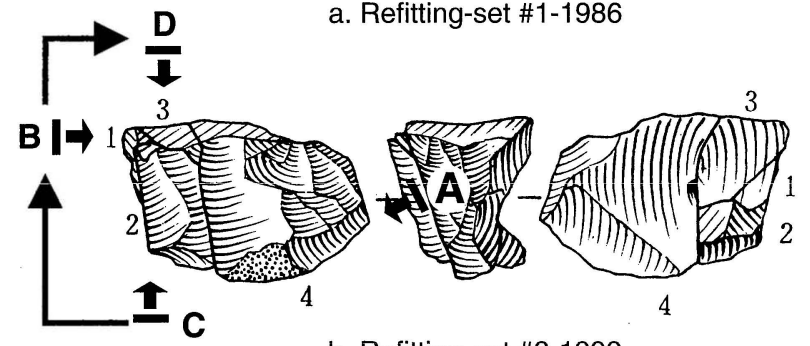

b. Refitting-set \#3-1992

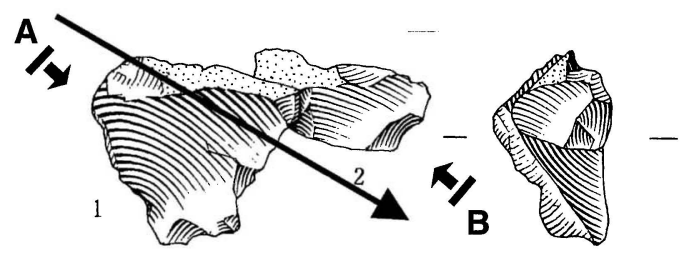

c. Refitting-set \#1-1992

Fig. 3. Reconstructed cores through refitting from Cenjiawan (after Xie et al. 1994 and Xie and Li 1995). Letters in bold linked with arrowed lines indicate striking platforms in sequential reduction.

Given the position of flake-striking platforms in the reconstruction, it is clear that the two flake removals were from opposite platforms of the core. Both flakes retain partial original cortex in the adjoined area, suggesting that these flake removals using two opposition platforms occurred at the early stage of core reduction.

The refitting success in the Cenjiawan lithic assemblages reveals a clear pattern of skillful flake removals with continuous rotation of cores. It is suggested that Cenjiawan cores have been utilized efficiently and effectively to obtain maximal flakes by employment of multiple platform reduction. Another important implication of the high refitting rate is that it suggests minimal disturbance of the site deposits. Since all of the lithic artifacts from the 1992 excavation were pieceplotted, the distribution of these refitting cores/flakes can be reconstructed. Xie and $\mathrm{Li}$ (1995) reported that about 80 percent of the refit pieces were from the artifact concentration area (squares $\mathrm{N}, \mathrm{O}, \mathrm{P}$, and $\mathrm{Q}$ ). The furthest distance between two pieces within a given refitting set is $3.57 \mathrm{~m}$, and the least distance is $0.16 \mathrm{~m}$. 
Over half of the refit pieces were on the same horizontal level. The data undoubtedly point to on-site core reduction activities, as well as the primary context of site formation (Schick et al. 1991; Xie and Li 1995).

\section{THE MALIANG SITE}

Maliang is located on a hillslope $300 \mathrm{~m}$ north of the Donggutuo village at the outer edge of the Nihewan Basin. Using the Donggutuo field datum as a reference, the distance between Donggutuo and Maliang is about $515 \mathrm{~m}$ with a bearing of $86^{\circ}$ (Fig. 1). The artifacts and fossils were found at a depth of $0.5 \mathrm{~m}$ in sediment of loose yellow to dark brown fine-grained sandy soil, on top of a layer of heavily bedded sand. The sediment of the site is suggestive of a fine-grained, high-energy fluvial sedimentary context (Schick et al. 1991). Thus, artifacts and faunal remains were most likely disturbed and redeposited at the site. The site was first identified in 1984, and excavated in 1985 by archaeologists from the Institute of Vertebrate Paleontology and Paleoanthropology, exposing $20 \mathrm{~m}^{2}$. In total, 121 lithic artifacts were recovered as well as faunal remains including mainly Palaeoloxodon sp., Equus sp., Coelodonta antiquitatis, and Cervids. The excavation was loosely controlled, with no detailed information on artifact provenience and no screening was applied.

Even though this lithic assemblage appears to have undergone postdepositional disturbance to some degree, it should be noted that lithic data retrieved from technological and functional examinations are still valid because the disturbance was mainly horizontal movement within the site due to hydraulic invasion. This is a common type of disturbance of cultural materials in Early and Middle Pleistocene sites in the Basin, due to the nature of this shore-side occupation. Shen and Chen (Chen and Shen 1999; Shen and Chen 2003) demonstrated that, based on analyses of site formation from Xiaochangliang, $2 \mathrm{~km}$ west of the Maliang, lithic artifacts were transferred only within the site. The examination of the lithic artifacts suggests that manufacturing activities took place there (also see Pope and Keates 1994). Therefore, examinations of lithic artifacts from Maliang, although in disturbed context, would still reveal evidence of core reduction technique as well as tool function at the site.

\section{The Lithic Assemblage}

Maliang lithic artifacts were probably collected with some bias given the field methods used at the time of excavation (e.g., no dry-screening). Small chips and chunks were not given much attention in the recovery process. Therefore, within the given lithic assemblage, unmodified flakes (28\%) and flaking debris (35.5\%) were predominant (Table 2). Flakes with intentional retouch on working edges account for 19 percent. Cores appear with single, double, and multiple platforms. The core morphology is characterized by multidirectional flake-car patterns, irregular but generally circular in shape, and moderate in size (Fig. 4). The mean core length, width, and thickness are $47.5 \mathrm{~mm}$ (S.D. $=13.5$ ), $40.9 \mathrm{~mm}$ (S.D. $=12.3)$, and $30 \mathrm{~mm}$ (S.D. = 9.1), respectively. Most cores fall into the range of 30-60 $\mathrm{mm}$ in length, $30-50 \mathrm{~mm}$ in width, and $20-40 \mathrm{~mm}$ in thickness.

Tools include two end-scrapers (Fig. $4 a, d$ ), one side-scraper (Fig. 4b), and one notch, a similar composition to that found in Cenjiawan. Scrapers and notches are 
Table 2. Lithic Assemblage of Maliang

\begin{tabular}{lccc}
\hline CLASS & N & & $\%$ \\
\hline Cores & 15 & 2 & 12.4 \\
$\quad$ core with single platform & & 9 & \\
$\quad$ core with dual platform & & 4 & \\
$\quad$ core with multiple platform & 29 & 2 & \\
Formed Types & & 1 & \\
$\quad$ end-scrapers & & 1 & \\
$\quad$ side-scrapers & & 2 & 28.0 \\
$\quad$ notches & & 23 & 35.5 \\
$\quad$ circular tablet objects & 34 & 34 & 100.0 \\
$\quad$ modified flakes & & & \\
$\quad$ unmoditage & 43 & & \\
Debris (chucks) & 121 & & \\
Total & & &
\end{tabular}

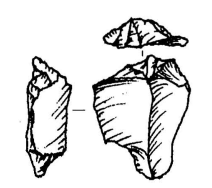

a. ML060

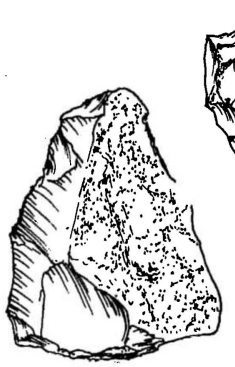

h. ML049
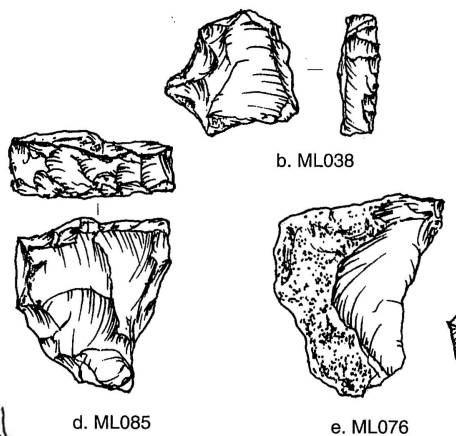

d. ML085
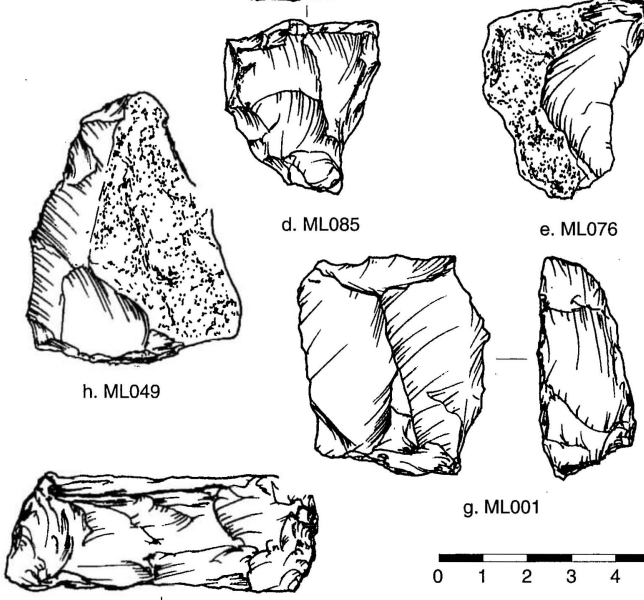

g. ML001
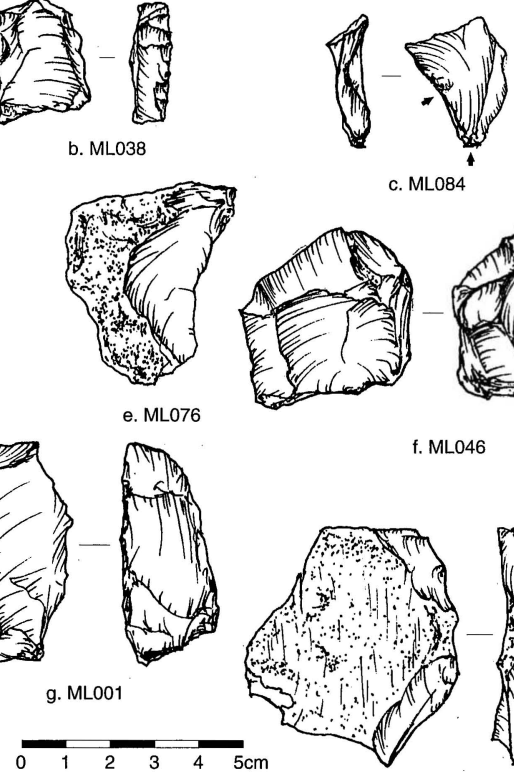

c. ML084

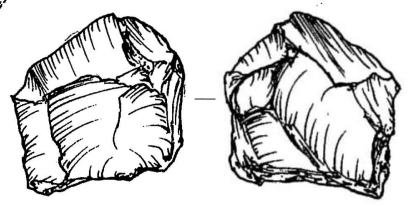

f. ML046

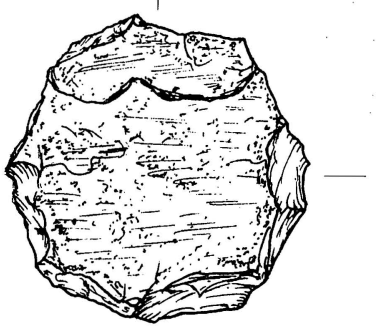

j. ML042
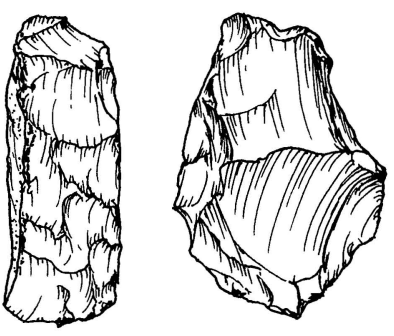

i. ML043
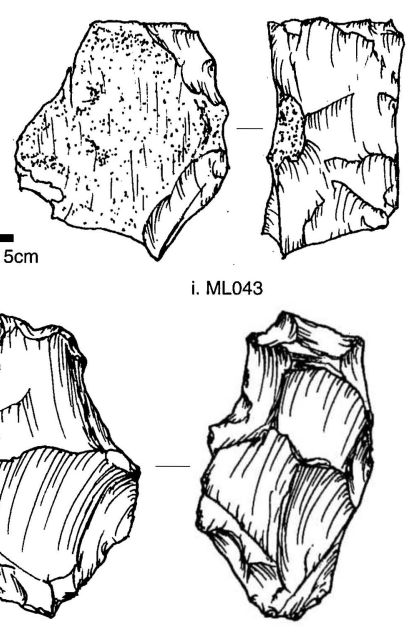

k. ML045

Fig. 4. Lithic artifacts from the Maliang site. Cores: $f$, $k$; end-scrapers: $a$, $d$; side-scraper: $b$; tabletshaped object: i, j; modified flake: g; flakes: $c, e, f$. 
Table 3. Size of Modified and Unmodified Flakes from Maliang

\begin{tabular}{lcccr}
\hline & AVG. LENGTH $\mathrm{mm}$ & S.D. & AVG. WIDTH $\mathrm{mm}$ & S.D. \\
\hline Modified Flakes & 38.1 & 10.1 & 29.5 & 9.7 \\
Unmodified Flakes & 34.3 & 15.0 & 29.8 & 14.1 \\
\hline
\end{tabular}

made on relatively small black or brown chert flakes. The retouch is regular and steep. In addition, two circular tablet-shaped objects were identified (Fig. $4 i, j$ ). While they are each of different raw materials, both were formed by modifying a flat tablet-shaped core into a round shape by flaking the periphery alternately from opposite surfaces that retain an entirely original cortex. In a way, both could serve as cores as well. Given the thickness of the cores $(<30 \mathrm{~mm})$, the flakes removed from these pieces would be short and broad. However, it is possible that the two circular tablet objects might have been modified as possible tools whose function is unknown.

Twenty-three pieces are identified as modified flakes whose edges have minimal retouch (Fig. $4 g$ ). Most of these pieces are made on flake blanks of small size (Table 3 ). The edge retouch is unifacial on the dorsal side, and segments of retouch are short. The average size of unmodified flakes is similar to that of the modified ones, suggesting that tool blanks were probably produced in some consistent way. Fifteen flakes retain some degree of cortex on the dorsal surface, therefore they may be considered primary and secondary flakes (Fig. $4 h, e$ ). There are a few flakes that retain previous platforms and flake removal scars that are classified as core-trimming flakes. One of these (ML084) shows evidence of the $90^{\circ}$ platform core reduction mode (Fig. 4c).

\section{The Technological Analysis}

All modified and unmodified flakes were examined for technological features of core reduction. Variables include flake breakage, percussion point and bulb appearance, cortex coverage, cortex location, dorsal scar pattern, and dorsal scar number.

Seventy-four percent of 71 modified and unmodified flakes examined are complete flakes. Fragmentary flakes are evenly distributed over the other four categories: distal end fragments (6.6\%), medial fragments (without distal or proximal end, 4.4\%), proximal fragments (with platform, 8.8\%), and lateral fragments (with both partial/broken distal and proximal ends, 4.4\%). The bulbar scar and point of percussion are clear features on nearly 80 percent of samples (Figs. 5 and 6). Very few of the flakes show crashed platforms and bulbs. The high percentage of complete flakes with clear percussion point and bulb scars, not only can be attributed to good quality of raw materials, but also suggest good control of flint knapping.

A high degree of flint-knapping skill is also supported by observing scar patterns and ridge orientation on the dorsal side of the flakes. For example, a parallel pattern along the axis of a flake may be indicative of desired blank detachment, given a series of continuous flake removals from the same platform. Nonparallel scar patterns may be the result of multiple orientation core reduction. Parallel-truncated and parallel-converging patterns are suggestive of ninety- 


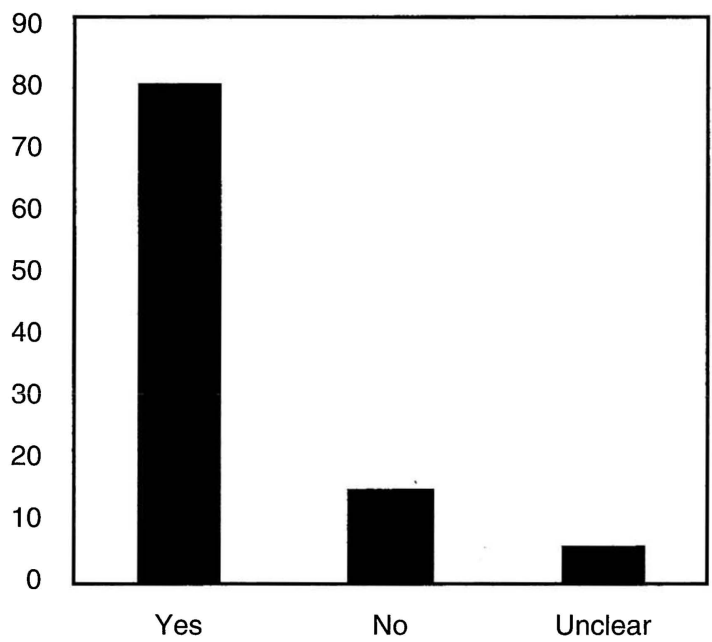

Fig. 5. Percussion point appearance $(\%)$.

degree rotation of the core during flake removal (see Shen 2001). From the sample examined, parallel scar patterns are clearly found on almost half $(43.5 \%)$ of the flakes (Fig. 7). Less than 30 percent of the flakes probably were produced through rotating core platforms resulting in flakes with parallel-converging and paralleltruncated patterns. Only a small number of flakes have irregular dorsal scar patterns. Nearly 30 percent of flakes with unrecognizable dorsal scar patterns are those with excessive cortex, suggestive of initial detachment.

Flakes were examined on all sides for cortex, because a number of flakes display cortex on their platforms (or proximal ends) as well as distal ends. Almost half the flakes have no cortex at all (Fig. 8). About 20 percent of the flakes are covered by 75 percent or more cortex on the dorsal surface while 34 percent of the flakes have less than 75 percent cortex. This pattern of cortex coverage distribution clearly implies that the different stages of core reduction are represented in

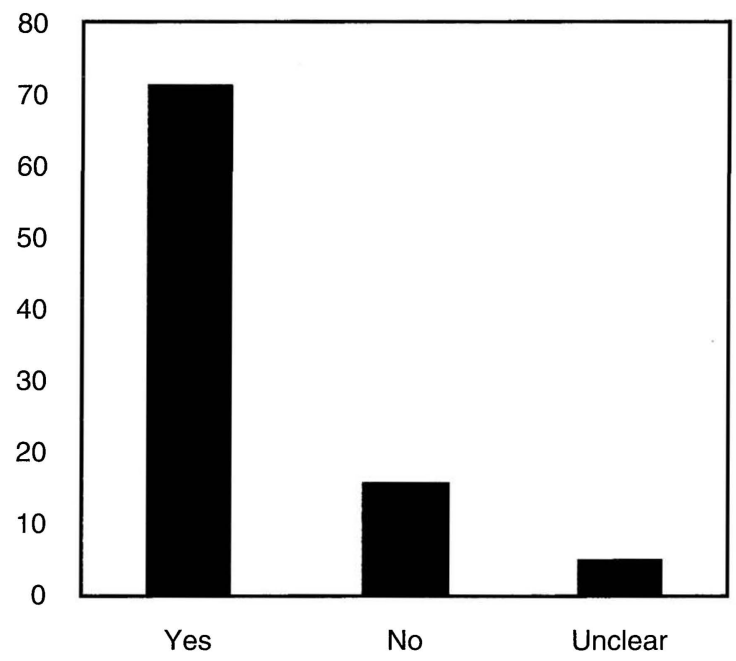

Fig. 6. Bulb scar appearance (\%). 


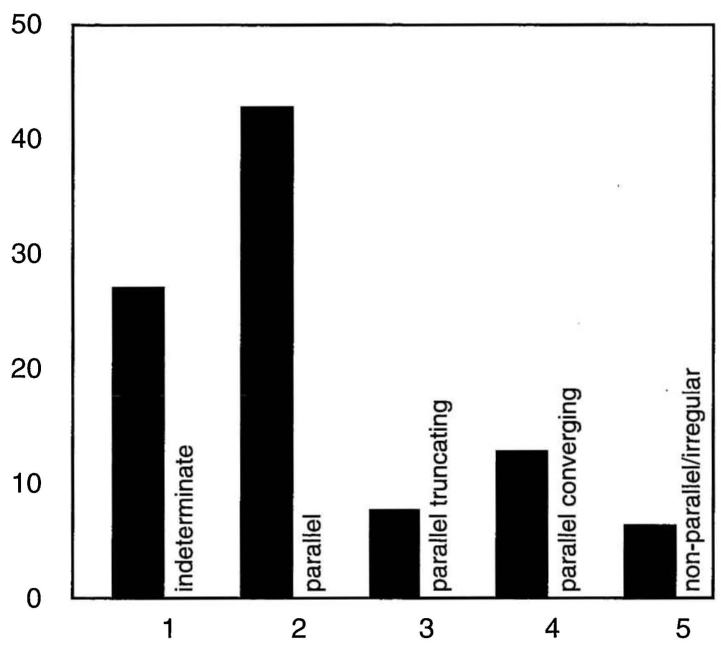

Fig. 7. Dorsal scar pattern (\%).

the assemblage. Among 35 flakes with cortex, 19.4 percent of the sample display cortex on all three parts: distal end, proximal end, and dorsal surface (Fig. 9), indicating that these flakes were primary flakes removed during initial core reduction stages. Flakes with proximal or distal cortex only account for 36 percent. These flakes must have been removed at intermediate stages when original surfaces of the core still served as platforms. Flakes with dorsal cortex only but no platform cortex or distal cortex comprise 8.1 percent of the samples, suggesting that a small number of flakes were removed at the early stages from a platform possibly created by previous flake removals.

Dorsal scar count is also a good indicator of the sequence of core reduction (see Andrefsky Jr. 1998:104-107; Shott 1996). Many of the flakes (43.8\%) have only a few (1-2) flake negative scars (Fig. 10). This figure is consistent with the numbers of flakes exhibiting cortex, suggesting that about half of the flakes found at

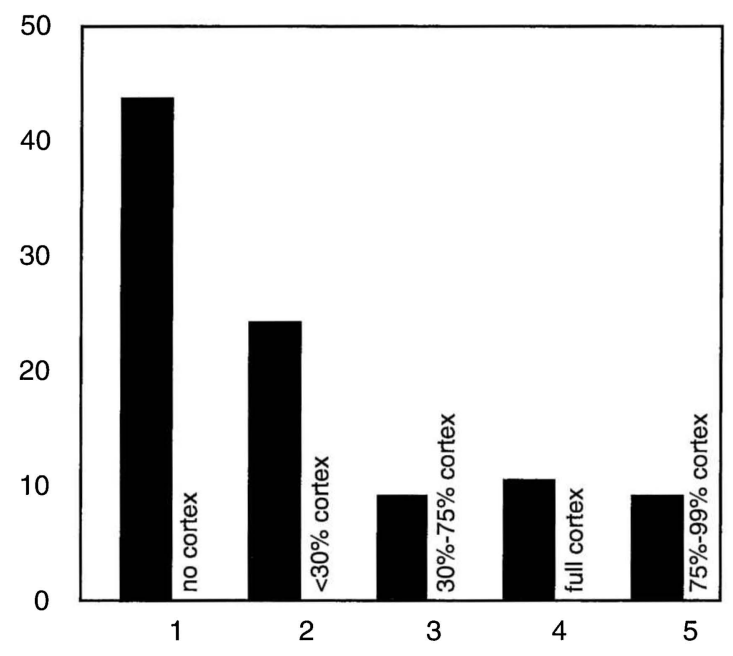

Fig. 8. Cortex coverage (\%). 


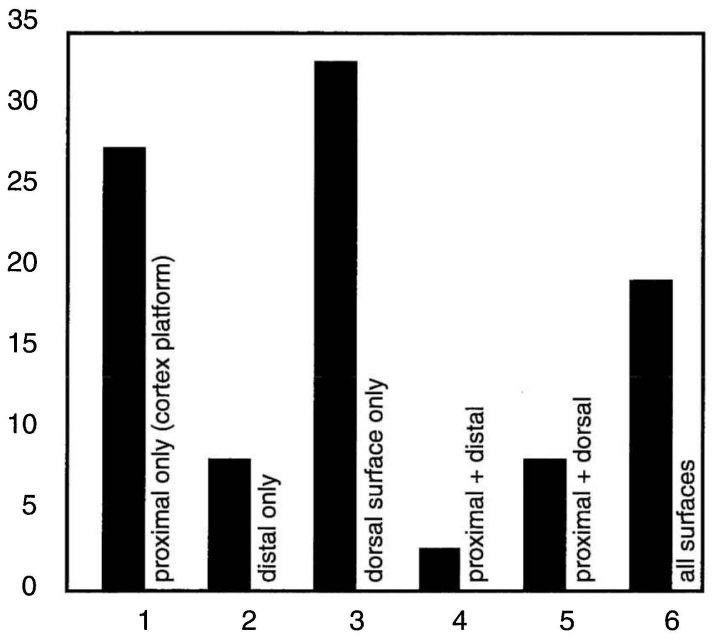

Fig. 9. Cortex location (\%).

the site were products of the early stages of core reduction. About 10 percent of flakes show high numbers of dorsal scars $(>5)$ that were clearly produced in the late stage of core reduction. It is notable that a number of flakes (28\%) have between 3 and 5 dorsal scars, suggesting a consistent proportion of flakes removed in the middle stages of core reduction.

The technological analyses of flake attributes infer that the site likely represents a manufacturing activity area, even though exact working floors were modified by inundation. However, further investigation at this site should verify this hypothesis.

\section{The Use-Wear Analysis}

The goal of the use-wear analysis is to examine possible patterning on the Maliang stone tools inferred from use-wear types, and to infer hominid's adaptive

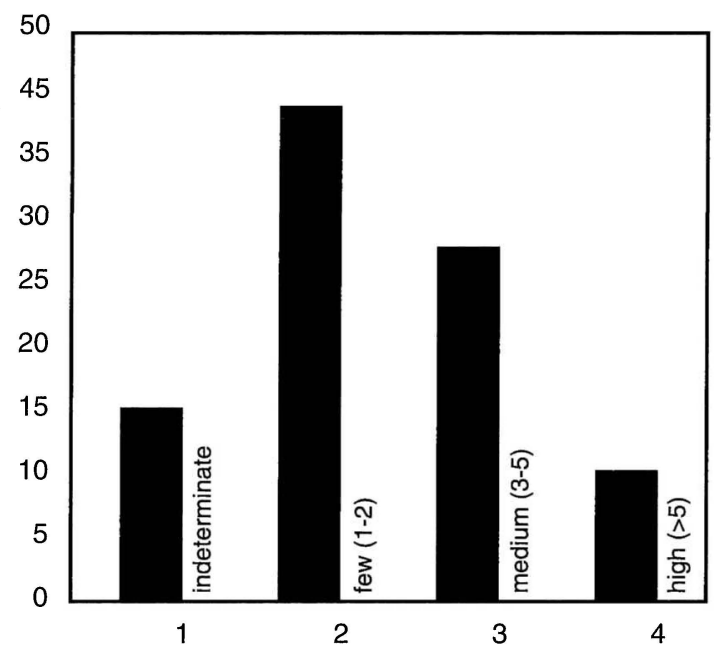

Fig. 10. Dorsal scar number (\%). 
Table 4. Tool Motion Use-Wear from Maliang Lithic Artifacts

\begin{tabular}{lcr}
\hline TOOL MOTION CATEGORY & NO. OF EdU & $\%$ \\
\hline cutting/sawing & 3 & 21.4 \\
slicing/carving & 1 & 7.1 \\
scraping/shaving & 9 & 64.3 \\
boring/drilling & 1 & 7.1 \\
Total & 14 & 100.0 \\
\hline
\end{tabular}

$\mathrm{EdU}=$ employed units.

behavior at the site. This study employed the low-power use-wear technique developed by Odell $(1981,1996)$, using a binocular microscope up to $300 \mathrm{x}$ magnification with reflective lighting. This technique examines the edge damage based on microfracture patterns and abrasion formation (polish, rounding, striation). The relevance of this technique applied to these earlier materials has been discussed elsewhere (see Shen 2001; Shen and Chen 2001, 2003). In total, 66 pieces, including formed types, modified flakes, and unmodified flakes, were examined.

Thirteen pieces were found with positive use-wear. Nine pieces were identified with ambiguous use-wear, which we labeled as possibly used pieces. The remaining 44 pieces exhibited no use-wear at all, therefore the use-wear rate of the Maliang assemblage is about 20 percent. All of the 13 utilized pieces, except one, have only one unit of edge segment defined as an employed unit (EdU). Flake ML060 has two employed units. Thus, the total use-wear EdU is 14. Two out of four scrapers/notches display clear use-wear, while only two retouched flakes seem to have been used. The remaining nine pieces fall in the category of unmodified flakes.

Use-wear types are found in association with four types of tool motions: cutting/sawing, slicing, scraping/shaving, and drilling (Table 4). The tool motion most commonly identified was scraping/shaving (64.3\%). This motion is consistent with morphological indications of the tool types in the assemblage (e.g., scrapers and notches). The next most common tool motion employed is cutting/ sawing, found on three EdU's (24.4\%). Indications of slicing and drilling activities were found on one piece each.

Use-wear types relating to worked materials are found evenly distributed in frequencies over the resistant-grade categories (Table 5). Five out of eight resistant-grade categories are involved, except for soft vegetal, medium-hard vegetal, and hard inorganic. Only one used segment of a flake is associated with medium-soft vegetal. It seems that activities at the Maliang site are involved with meat processing and bone working. The use-wear patterns of three pieces $(21.3 \%)$ could not be assessed to any of the resistant-grade categories.

We have distinguished eight kinds of tool use tasks. Four flake tools were employed for scraping hard bone (Fig. 11a), while two pieces were used for scraping animal hide or skin. Three pieces were used for cutting animal meat or hide, butchering animals (with resistance from fresh bone) or processing fish, and cutting/sawing very hard and dry bone (Fig. 11b), respectively. One piece was involved in slicing meat off fresh bone, while the other one was employed to 
Table 5. Worked Material Use-Wear from Maliang Lithic Artifacts

\begin{tabular}{lcr}
\hline WORKED MATERIAL CATEGORY & NO. OF EdU & $\%$ \\
\hline Indeterminate & 3 & 21.4 \\
soft animal (SA) & 3 & 21.4 \\
soft vegetal (SV) & 0 & 0.0 \\
medium-soft vegetal (1M) & 1 & 7.1 \\
medium animal (MA) & 2 & 14.3 \\
medium-hard vegetal (2M) & 0 & 0.0 \\
hard animal (1H) & 3 & 21.4 \\
very hard animal (2H) & 2 & 14.3 \\
hard inorganic (3H) & 0 & 0.0 \\
Total & & \\
\hline
\end{tabular}

$\mathrm{EdU}=$ employed units.

scrape fresh tree/wood (Fig. $11 c-d$ ). There are two additional scraping tools and one drilling tool, but worked materials remain unknown.

\section{DISCUSSION AND SUMMARY}

Our study of the lithic industries from these Middle Pleistocene Nihewan Basin sites proposes some aspects of lithic technology that are unique and as yet unidentified at contemporaneous localities in the region. Recent studies of other Lower Paleolithic lithic assemblages (Xiaochangliang, Donggutuo, Zhoukoudian Localities 1 and 15) have provided comparative data (Chen et al. 1999, 2002; Gao 2000a, 2000b, 2001; Hou 1992, 2000; Keates 2000; Pei and Zhang 1985) that allow us to discuss lithic technological variability in northern China.

Raw materials for tool making at both Maliang and Cenjiawan are finegrained, high-quality volcanic cherts of brown, creamy white, and black color. However, these locally available high-quality raw materials were not found at the Early Pleistocene upland sites of Xiaochangliang and Donggutuo $1500 \mathrm{~m}$ to the west (Fig. 1). The lithic assemblages from these sites were predominantly poorquality, coarse-grained cherts (Chen et al. 1999; Keates 2000; Pope and Keates 1994; You et al. 1978). The exploration of different raw materials available locally to early hominids from these sites needs to be further investigated. Our results suggest, however, that the hominids at Maliang and Cenjiawan might have intentionally selected good-quality raw materials.

The core morphology and flaking property point to a hard-hammer percussion, core reduction mode at both the Maliang and Cenjiawan sites. A multiplatform flake removal strategy is recognized through refitting and attributes analyses. This core reduction practice-continuously rotating the core and creating new platforms for suitable flake removals - utilized a core nodule to near exhaustion. As a result, flakes at both sites were carefully planned and skillfully removed. Nevertheless, prepared-platform core reduction technique is not evident. At Maliang, both early stages and later stages of core reduction took place on-site, indicating tool manufacturing activities, although the deposit may not be in primary context. On-site manufacturing activities at Cenjiawan are clearly suggested through reconstructed core nodules in the primary context. 


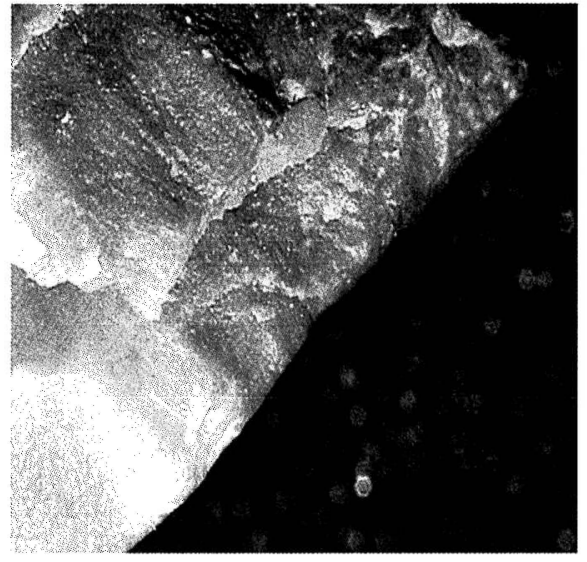

a. ML085, 14×. heavily rounded edge with used polish along the working edge, scatted scars are moderate to large in size with stepped and hinged termination, unifacially distributed on the dorsal surface. The wear type is indicative of scraping hard bone.

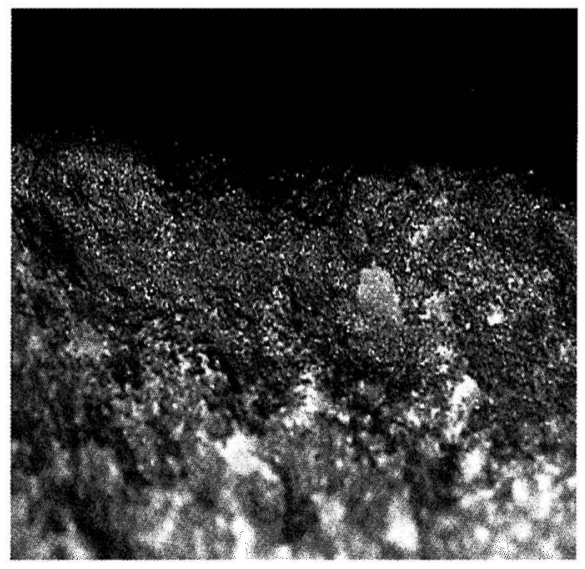

c: ML060, dorsal side, $56 \times$. small to moderator sized feathered or hinged scars, unifacially distributed along the edge on dorsal side.

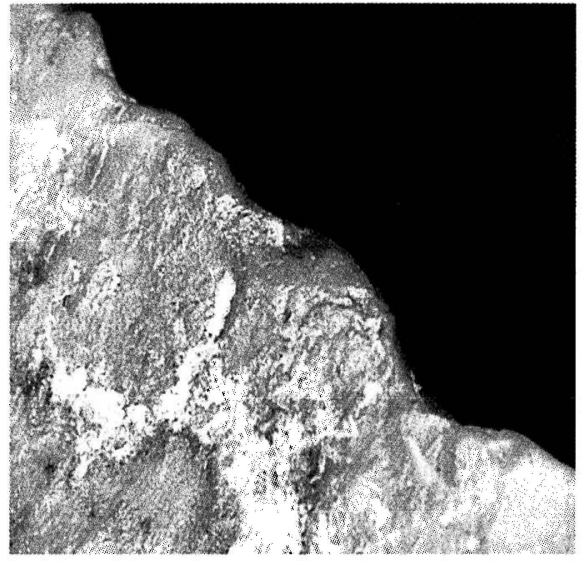

b. ML001, 28×. moderate to large scars bifacially distributed along the edge of 10$15 \mathrm{~mm}$. Scars are directional but most are vertical to the edge, heavy rounding and rare polish. Interpreted as cutting/sawing hard bones use-wear.

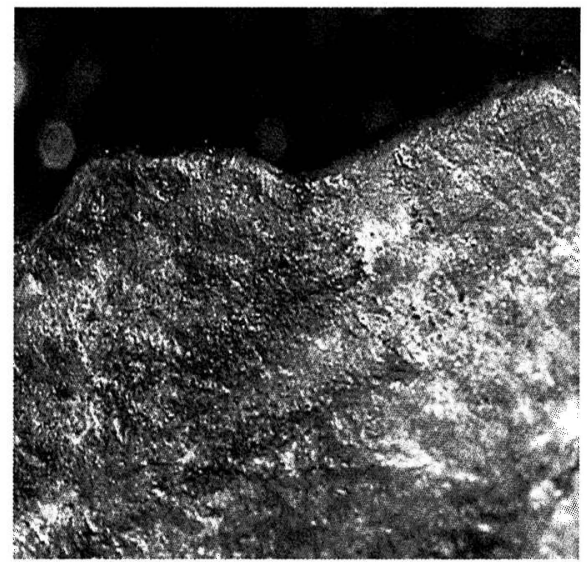

d: ML060, ventral side, $28 \times$. heavy rounding and polish along ventral sided working edge (as opposite to that in previous photo). A few striation parallel or perpendicular to the edge are noted. The combination of wear patterns are suggestive of scraping wood use-wear.

Fig. 11. Use-wear of Maliang lithic artifacts.

This multidirectional flake removal strategy is also seen at Zhoukoudian Locality 15, situated near Beijing approximately $130 \mathrm{~km}$ southeast of the Nihewan Basin. It is worth noting that at the early Late Pleistocene site of Zhoukoudian Locality 15 , a relatively complicated core-reduction mode was labeled as alternate flaking reduction by Gao $(2000 a, 2000 b)$. This special technique resulted in a relatively high frequency of discoid cores at the site, but core platform preparation 
Percussion Point Appearance

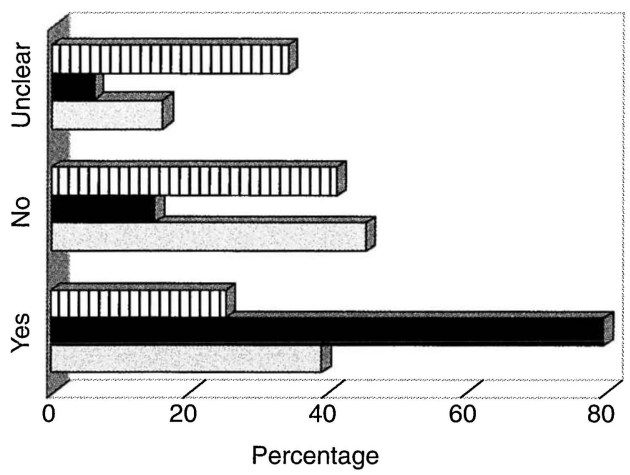

एIIII Zhoukoudian Locality 15
Bulb Scar Appearance

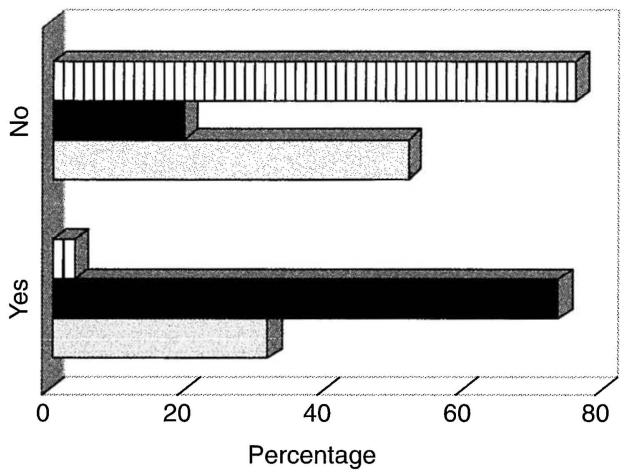

Xiaochangliang

Fig. 12. Technological comparison on percussion point and bulb scar among Zhoukoudian Locality 15, Maliang, and Xiaochangliang (Data on Zhoukoudian Locality 15 drawn from Gao 2000b).

was not suggested. From the earlier assemblage of Xiaochangliang, core reduction is represented by expedient and unstandardized flake removals (Chen et al. 1999, 2002; Keates 2000). There is no evidence of multidirectional reduction. Flake removals were casual, resulting in a large number of core fragments and small irregular cores. At Donggutuo, core reduction shares similar features of Xiaochangliang (Keates 2000), but some cores display clear traces of flake removal sequences. Recently Hou (2000) argued that a special core reduction strategy involving core preparation was observed at Donggutuo. Our own observations suggest that although Donggutuo cores do show more sophisticated features than Xiaochangliang cores, there is not enough evidence to qualify Douggutuo cores as platform-prepared, wedge-shaped cores as Hou claimed.

In addition, bipolar percussion was observed at both Zhoukoudian Locality 1 and Locality 15 as well as at Xiaochangliang. At Zhoukoudian, bipolar reduction was employed most extensively as a strategy to utilize quartz and poor-quality quartzite. It is not clear yet whether use of bipolar technique at Xiaochangliang had something to do with the poor quality of raw materials. However, no technological evidence suggests such reduction was employed at Maliang and Cenjiawan, although a small number of bipolar-like core and flakes were identified in the Cenjiawan site.

The differences in the core reduction strategies among these sites could be attributed to the fact that high-quality cherts may have been intentionally selected by Maliang and Cenjiawan hominids during the Middle Pleistocene. The lack of percussion points and bulb scars observed at both Xiaochangliang and Zhoukoudian Locality 15 is due to the use of poor-quality raw materials (Fig. 12) (Chen et al. 1999; Gao 2000b; Keates 2000). More flake fragments and a higher frequency of flakes with nonpatterned or indeterminate patterned dorsal scars are present at Xiaochangliang than at Maliang (Fig. 13). The intentional selection and use of high-quality raw materials at Maliang, materials that were also available at Xiaochangliang, possibly reflect evolutionary adaptive behavior by the Maliang hominids. 
Flake Breakage

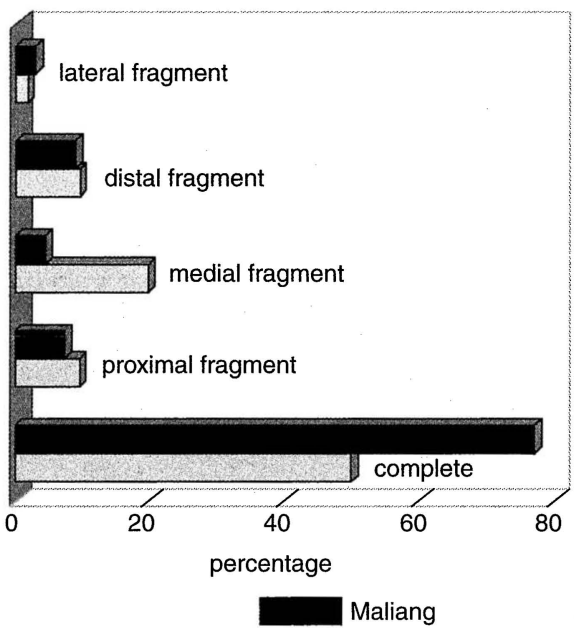

Dorsal Scar Pattern

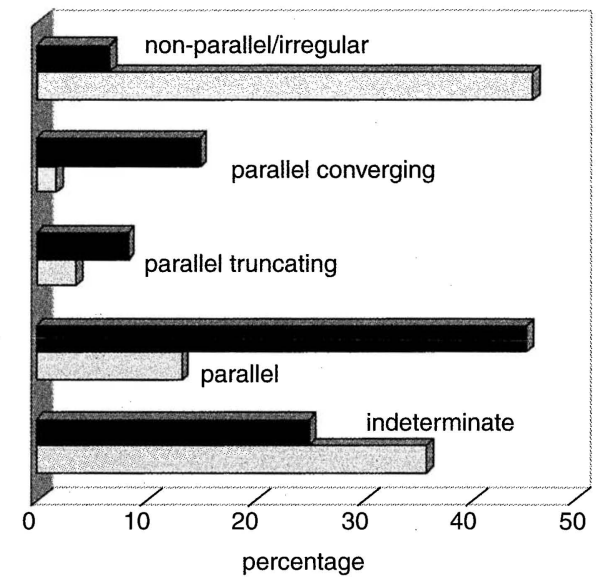

Xiaochangliang

Fig. 13. Technological comparison on flake breakage and dorsal scar pattern between Maliang and Xiaochangliang.

Tool production at Cenjiawan and Maliang is represented by predominantly modified flakes. Scrapers or notches are the only tool forms. The retouched flakes present minimal modification. Tool utilization at Maliang is characterized by activities involving scraping and shaving. Based on microscopic examination of use-wear, the tool tasks were dominated by meat processing and bone working.

Drawing from the comparative use-wear data from Xiaochangliang (Chen et al. 2002; Shen and Chen 2000, 2001, 2003) and Zhoukoudian Locality 1 (Hou 1992), some use-patterning of stone tools at these three sites can be compared. Studies of Xiaochangliang and Zhoukoudian Locality 1 lithic use-wear suggest that cutting/sawing/slicing tasks were as frequent as scraping/shaving, while tool use at Maliang probably emphasized scraping/shaving activities. Rotating activities like drilling were found at both Xiaochangliang and Maliang, but not at Zhoukoudian Locality 1 . According to the types of worked materials, Maliang differs from the other two localities. Both Xiaochangliang and Zhoukoudian Locality 1 stone tools might have been employed more in woodworking than the Maliang stone tools, although meat-processing activities were clearly a main feature of use-patterning at all sites. Compared to the Maliang site, both Xiaochangliang and Zhoukoudian Locality 1 have fewer tools that were employed in bone working. The differences in tool use among the three sites suggest possible different food procurement strategies by early hominids at these sites. Given the somewhat biased samples examined in these studies, however, further investigations are needed to test these hypotheses.

\section{CONCLUSION}

This study demonstrates that although lithic industries during the Early and Middle Pleistocene in East Asia could be generalized as "simple core-flake technology," or "Mode 1 technology" (Schick 1998; Schick and Dong 1994), the 
Maliang and Cenjiawan lithic assemblages represent regional and/or temporal variations of Lower Paleolithic lithic industries in northern China. This lithic technological variability may simply reflect hominid adaptive strategies to different environments and cultural interactions. It is suggested that before hominid behaviors in East Asia can be interpreted, an understanding of lithic technological variability in northern China is essential.

\section{ACKNOWLEDGMENTS}

The Royal Ontario Museum Foundation provided financial support, which made this research possible. We wish to thank the Panxian Dadong Collaborative Project, led by Lynne Schepartz, Sari Miller-Antonio, Deborah, Huang Weiwen, and Hou Yamei, for the invitation to the conference, Asia and the Middle Pleistocene in Global Perspective, where an earlier draft of this paper was presented. We thank Sari MillerAntonio, Susan Keates, George Odell, and an anonymous reviewer for insightful comments. Shen would like to thank colleagues in China who provided generous help for the ROM-China Nihewan project: Chen Chun, Chen Shengquan, Xei Fei, Gao Xing, Li Jun, Pei Shuwen, and Wang Youping.

NOTE

1. Schick et al. (1991:19) erroneously reported an excavated area of $40 \mathrm{~m}^{2}$.

\section{REFERENCES CITED}

ANDREFSKy, William JR.

1998 Lithics: Macroscopic Approaches to Analysis. Cambridge: Cambridge University Press.

Barbour, George B.

1924 Preliminary observation in the Kalgan area. Bulletin of the Geological Society of China 3(3) : 167-168.

Barbour, George B., Emile Licent, and Pierre Teilhard de Chardin

1927 Geological study of the deposits of the Sangkaoho basin. Bulletin of the Geological Society of China 6(3): 263-278.

Chen Chun, Chen Shen, Chen Wanyong, and Tang Yinjun

19991998 excavation of the Xiaochangliang site at Yangyuan, Hebei [in Chinese with English abstract]. Acta Anthropologic Sinica 18(3):225-238.

2002 A study of the Xiaochangliang lithic industry [in Chinese with English abstract]. Acta Anthropologic Sinica 21(1):23-40.

GAO XING

$2000 a$ A study of flaking technology at Zhoukoudian Locality 15 [in Chinese with English abstract]. Acta Anthropologica Sinica 19(3): 199-215.

2000 b Core reduction at Zhoukoudian Locality 15. Archaeology, Ethnology E Anthropology of Eurasia 3:2-12.

2001 A study of stone tool typology and retouch technology at Zhoukoudian Locality 15 [in Chinese with English abstract]. Acta Anthropologica Sinica 20(1):1-18.

Hou YameI

1992 Preliminary microwear studies on archaeological stone artifacts [in Chinese with English abstract]. Acta Anthropologica Sinica 11(4):354-361.

2000 Donggutuo lithic industry of the Nihewan basin, north China. Unpublished Ph.D. diss. Institute of Vertebrate Paleontology and Paleoanthropology, Chinese Academy of Science, Beijing.

Huang Weiwen, Hou Yamei, and Si Xinqiang

1997 Stone industry from Panxian Dadong, a cave-site of southeastern China [in Chinese with English abstract]. Acta Anthropologic Sinica 16(3): 171-192. 
Keates, Susan G.

2000 Early and Middle Pleistocene Hominid Behaviour in Northern China. BAR International Series 863. Oxford: John and Erica Hedge Inc.

LENG JIAN

2001 Early Paleolithic technology in Eastern and Southern Asia. BAR International Series 924. Oxford: John and Erica Hedge Inc.

LU, ZUN'ER

1999 Some remarks on pebble tool industries after a visit to Gongyi and Luonan [in Chinese]. Archaeology and Cultural Relics No. 1:27-35.

Movius, Hallum L.

1944 Early man and Pleistocene stratigraphy in southern and eastern Asia. Papers of the Peabody Museum of American Archaeology and Ethnology XIX(3): 1-125.

1948 The Lower Paleolithic cultures of southern and eastern Asia. 38 part. 4:329-420.

1969 Lower Paleolithic archaeology in southern Asia and the Far East. Reprinted in W. W. Howells (ed.): 17-82, Early Man in the Far East, Studies in Physical Anthropology No. 1. New York: Humanities Press.

Odell, George H.

1981 The mechanics of use-breakage of stone tools: Some testable hypotheses. Journal of Field Archaeology 8:197-209.

1996 Stone Tools and Mobility in the Illinois Valley: From Hunter-Gatherer Camps to Agricultural Villages. International Monographs in Prehistory. Ann Arbor: University of Michigan.

Olsen, John W., And Sari Miller-Antonio

1992 The Palaeolithic in southern China. Asian Perspectives 31(2):129-160.

Pei Wenzhong, and Zhang Senshui

1985 A Study on the Lithic Artifacts of Sinanthropus [in Chinese with English abstract]. Beijing: Science Press.

Pope, Geoffrey G., and Susan G. Keates

1994 The Evolution of Human Cognition and Cultural Capacity: A view from the Far East, in Integrative Paths to the Past: Paleoanthropological Advances in Honor of F. Clark Howell: 531568, ed. R. S. Curruccini and R. L. Ciochon. Englewood Cliffs, N.J.: Prentice Hall.

SCHICK, KATHY D.

1994 The Movius Line reconsidered: Perspectives on the earlier Paleolithic of Eastern Asia, in Integrative Paths to the Past: Paleoanthropological Advances in Honor of F. Clark Howell: 569596, ed. R. S. Corruccini and R. L. Ciochon. Englewood Cliffs, N.J.: Prentice Hall.

1998 A comparative perspective on Paleolithic cultural patterns, in Neandertals and Modern Humans in Western Asia: 449-460, ed. T. Akazawa, K. Aoki, and O. Bar-Yosef. New York: Plenum Press.

Schick, Kathy D., AND Dong Zhuan

1993 Early Paleolithic of China and eastern Asia. Evolutionary Anthropology 2(1):22-35.

Schick, Kathy, Nicholas Toth, Wei Qi, J. Desmond Clark, and Dennis Etler

1991 Archaeological perspectives in Nihewan Basin, China. Journal of Human Evolution 21 : 1321.

SHen, Chen

2001 The Lithic Production of the Princess Point Complex during the Transition to Agriculture in Southwestern Ontario, Canada. BAR International Series 991. Oxford: John and Erica Hedge Inc.

Shen, Chen, and Chen Chun

2000 A use-wear study of lithic artifacts from Xiaochangliang and hominids activities in the Nihewan basin [in Chinese with English abstract]. Acta Anthropologica Sinica, Supplement to Vol. 19(3) : 119-125.

2001 The use-wear analysis (low-power method): Research and practice-A case study of the Xiaochangliang lithic artifacts [in Chinese with English abstract]. Kaogu (Archaeology) (7) :55-61.

2003 New evidence of hominid behaviour from Xiaochangliang, North China: site formation and lithic technology, in Current Research in Chinese Pleistocene Archaeology: 67-82, ed. C. Shen and S. G. Keates. British Archaeological Report International Series \#1179. Oxford: Archaeopress. 
Shott, Michael J.

1996 Stage versus continuum in the debris assembglage from production of a fluted biface. Lithic Technology 21(1):6-22.

WANG YOUPING

1997 Pleistocene Environment and Paleolithic Cultures of Southern China [in Chinese with English abstract]. Beijing: Beijing University Press.

2001 New perspectives on studies of early hominids and Paleolithic cultures in China [in Chinese]. Chinese Cultural Relics News, January 3.

WEI QI

1991 Geological Formation sequence of the archaeological sites in the Nihewan basin, northern China, in Proceeding of the 13th Quaternary International Conference: 61-73. Beijing: Beijing Science and Technology Press.

1997 The framework of archaeological geology of the Nihewan basin [in Chinese with English abstract], in Evidence for Evolution: Essays in Honor of Prof. Chungchien Young on the Hundredth Anniversary of his Birth: 193-208, ed. by Y. S. Tong, Y. Y. Zhang, W. Y. Wu, J. L. Li, and L. Q. Si. Beijing: Ocean Press.

XIA, Z. K.

1992 The Study of the Change of Ancient Lake Shore in the Datong-Yangyan (Nihewan) Basin. Geographical Research 11(2):52-59.

Xie Fei, and Chen Shengquan

1990 Lithic artifacts recovered from Cenjiawen, a palaeolithic site at Yangyuan county of Hebei province [in Chinese]. Acta Anthropologica Sinica 9(3):265-273.

XIE FeI, AND J. LI

1993 Cultural remains and nature of Cenjiawan, a Lower Paleolithic site [in Chinese]. Acta Anthropological Sinica 12(3):224-234.

1995 The refitting application in the comprehensive analysis of the Cenjiawan lithic artifacts. Journal of Chinese Antiquity (1):25-38.

Xie F., K. D. Schick, N. Toth, and J. D. Clark

1994 A refitting study of lithic artifacts recovered from a 1986 excavation at Cenjiawan [in Chinese]. Journal of Chinese Antiquity (3):86-102.

You, Y., Y. TANG, AND Y. LI

1978 Paleolithic discoveries in the Nihewan Formation. Chinese Quaternary Research 1(5):1-13.

ZHANG, S. S.

1999 On the important advancements of the Paleolithic Archaeology in China since 1949. Acta Anthropologica Sinica 18(3):193-225.

\section{ABSTRACT}

Previous studies have generalized the technological character of the Lower Paleolithic of China with reference to its non-Acheulean features, but regional perspectives on technological variability were largely overlooked. This study examines two lithic assemblages from Middle Pleistocene sites in the Nihewan Basin in northern China: Cenjiawan and Maliang. Through applications of refitting analysis, technological analysis, and use-wear examinations, technological variability within these assemblages is assessed. The results reveal some aspects of lithic technology that were largely undocumented in Lower Paleolithic industries, such as intentional selection of high-quality raw materials, continuously rotating core reduction, and evidence for butchering/meat-processing tool use, suggesting that the Cenjiawan and Maliang lithic assemblages might represent regional and/or temporal variations of Lower Paleolithic industries in northern China. The data are compared to other Lower Paleolithic industries such as Xiaochangliang, Dongguotou, and Zhoukoudian (Localities 1 and 15). Keywords: Lower Paleolithic, lithic technology, core reduction, refitting, use-wear. 